\title{
Novel SMAC-mimetics synergistically stimulate melanoma cell death in combination with TRAIL and Bortezomib
}

\author{
D Lecis', C Drago², L Manzoni ${ }^{2,3}$, P Seneci, ${ }^{2,4}$, C Scolastico ${ }^{2}$, E Mastrangelo ${ }^{5,6}$, M Bolognesi $^{5,6}$, A Anichini', \\ H Kashkar ${ }^{7}, \mathrm{H}$ Walczak $^{8}$ and D Delia*,
}

'Department of Experimental Oncology, Fondazione IRCCS Istituto Nazionale Tumori, Via G Venezian I, 20133 Milano, Italy; ${ }^{2}$ Centro Interdisciplinare di Studi Biomolecolari e Applicazioni Industriali (CISI), Università degli Studi di Milano, Via Fantoli I6/I5, 20I 38 Milano, Italy; ${ }^{3}$ stituto di Scienze e Tecnologie Molecolari (ISTM), Consiglio Nazionale delle Ricerche (CNR), Via Fantoli I6/I 5, 20 I 38 Milano, Italy; ${ }^{4}$ Dipartimento di Chimica Organica e Industriale, Università degli Studi di Milano, Via Venezian 21, 20133 Milano, Italy; ${ }^{5}$ Dipartimento di Scienze Biomolecolari e Biotecnologie e CNR-INFM, Università degli Studi di Milano, Via Celoria 26, 20133 Milano, Italy; ${ }^{6}$ CNR-INFM S3, National Research Center on Nanostructure and BioSystems at Surfaces, Via Campi 2 I 3/A, 4 I I 00-Modena, Italy; ${ }^{7}$ Institute for Medical Microbiology, Immunology and Hygiene, University of Cologne, Goldenfelsstrasse 19-2 I, 50935 Köln, Germany; ${ }^{8}$ Department of Medicine, Tumour Immunology Unit, Imperial College London, Hammersmith Hospital Campus, I Oth floor, Commonwealth Building, Du Cane Road, London WI 2 ONN, UK

BACKGROUND: XIAP (X-linked inhibitor of apoptosis protein) is an anti-apoptotic protein exerting its activity by binding and suppressing caspases. As XIAP is overexpressed in several tumours, in which it apparently contributes to chemoresistance, and because its activity in vivo is antagonised by second mitochondria-derived activator of caspase (SMAC)/direct inhibitor of apoptosisbinding protein with low pl, small molecules mimicking SMAC (so called SMAC-mimetics) can potentially overcome tumour resistance by promoting apoptosis.

METHODS: Three homodimeric compounds were synthesised tethering a monomeric SMAC-mimetic with different linkers and their affinity binding for the baculoviral inhibitor repeats domains of XIAP measured by fluorescent polarisation assay. The apoptotic activity of these molecules, alone or in combination with tumour necrosis factor-related apoptosis-inducing ligand (TRAIL) and/or Bortezomib, was tested in melanoma cell lines by MTT viability assays and western blot analysis of activated caspases.

RESULTS: We show that in melanoma cell lines, which are typically resistant to chemotherapeutic agents, XIAP knock-down sensitises cells to TRAIL treatment in vitro, also favouring the accumulation of cleaved caspase-8. We also describe a new series of 4-substituted azabicyclo[5.3.0]alkane monomeric and dimeric SMAC-mimetics that target various members of the IAP family and powerfully synergise at submicromolar concentrations with TRAIL in inducing cell death. Finally, we show that the simultaneous administration of newly developed SMAC-mimetics with Bortezomib potently triggers apoptosis in a melanoma cell line resistant to the combined effect of SMAC-mimetics and TRAIL.

CONCLUSION: Hence, the newly developed SMAC-mimetics effectively synergise with TRAIL and Bortezomib in inducing cell death. These findings warrant further preclinical studies in vivo to verify the anticancer effectiveness of the combination of these agents. British Journal of Cancer (2010) 102, 1707-17|6. doi:10.1038/sj.bjc.6605687 www.bjcancer.com

Published online I I May 2010

(C) 2010 Cancer Research UK

Keywords: SMAC-mimetics; TRAIL; apoptosis; melanoma

Members of the IAP (inhibitor of apoptosis protein) family are key regulators of apoptosis and of clinical prognostic value in cancer (Kempkensteffen et al, 2007). Together with cellular IAP (cIAP) 1 and 2, XIAP (X-linked IAP) is one of the three most studied IAPs. The structure of XIAP is characterised by three N-terminal tandem repeat domains, called BIRs (baculoviral inhibitor repeats), peculiar of the IAP family, and a C-terminal RING (really interesting new gene) finger, endowed with E3 ubiquitin-ligase function. XIAP is a major negative regulator of apoptosis, a property dependent on its BIR domains (Takahashi et al, 1998) that bind to and inhibit both initiator caspase-9 and effector caspases 3 and 7 (Deveraux et al, 1997). cIAP1 and cIAP2, also

*Correspondence: Dr D Delia;

E-mail: domenico.delia@istitutotumori.mi.it

Received 29 January 2010; accepted 12 April 20 I0; published online II May 2010 bind caspases (Eckelman and Salvesen, 2006) but the biological significance of this interaction is less well understood. XIAP can regulate caspases and other proteins, not only by binding and sequestering them, but also by ubiquitination and consequent proteasome-dependent degradation.

The activity of XIAP is antagonised by SMAC/DIABLO (second mitochondria-derived activator of caspase/direct inhibitor of apoptosis-binding protein with low $\mathrm{pI}$ ), that, on release from mitochondria in response to apoptotic stimuli (Du et al, 2000), undergoes maturation and cleavage of its $\mathrm{N}$-terminal region, allowing the exposure of the AVPI sequence. This tetrapeptide binds XIAP (Wu et al, 2000) and competes with the same binding sites that are responsible for the interaction with caspases (Liu et al, 2000). In this way, SMAC/DIABLO prevents the sequestration of caspases, facilitating the apoptotic pathway. As the AVPI sequence can promote apoptosis, compounds mimicking this tetrapeptide, called SMAC-mimetics, have become 
the focus of intense research (Li et al, 2004; Oost et al, 2004; Mastrangelo et al, 2008) as pro-apoptotic pharmacological agents for cancer treatment (Sun et al, 2006). Accordingly, several XIAP-targeting SMAC-mimetics have been developed. Intriguingly, they were also found to target other members of the IAP family, especially cIAP1 and cIAP2 (Varfolomeev et al, 2007; Vince et al, 2007; Galbán et al, 2009). To improve their activity, dimeric SMAC-mimetics formed by two binding heads tethered by a chemical linker, were recently generated and shown to be more potent than the monomeric counterparts (Li et al, 2004; Lu et al, 2008) because of the simultaneous binding to two BIR domains (Cossu et al, 2009b).

In some cell lines, SMAC-mimetics as single agents elicit cell death through the extrinsic apoptotic pathway (Gaither et al, 2007) triggered by autocrine production of tumour necrosis factor (TNF) (Petersen et al, 2007; Varfolomeev et al, 2007; Vince et al, 2007; Wang et al, 2008) and requiring caspase-8 activation (Bertrand et al, 2008). In the vast majority of cancer cells, however, SMAC-mimetics as single agents are poorly cytotoxic (Petersen et al, 2007), although they can potently synergise with the apoptosis-inducing ligands of the TNF superfamily ( $\mathrm{Li}$ et al, 2004). Although TNF and CD95 ligand (CD95L/FasL) are unsuitable for cancer treatment because of their systemic inflammatory effects (Lejeune et al, 1998) and hepatotoxicity (Walczak et al, 1999), respectively, the TNF-related apoptosisinducing ligand (TRAIL) is an extremely promising biotherapeutic, owing to its potency and limited side effects (Ashkenazi and Herbst, 2008). In spite of the fact that $50 \%$ of tumour cell lines are TRAIL-sensitive, it was recently shown that primary tumour cells derived from human breast, lung and colon tumours are often TRAIL-resistant (Todaro et al, 2008). Although TRAIL has been suggested for treatment of melanoma (Kurbanov et al, 2005), a tumour typically resistant to chemotherapy, also melanomas are often unresponsive to TRAIL-induced apoptosis (Kurbanov et al, 2006). Therefore, it is important to identify drugs, which when used in combination with TRAIL, can overcome this resistance.

In this study, we show that human melanoma cell lines can be sensitised to TRAIL in vitro by knocking down XIAP by shRNA interference. Furthermore, Bortezomib, a proteasome inhibitor currently used in cancer treatment, can also sensitise melanoma cells to TRAIL. Finally, we describe new SMAC-mimetic compounds, synthesised on the basis of structure-based approaches that markedly synergise with TRAIL in killing melanoma cells.

\section{MATERIALS AND METHODS}

\section{Cell culture and reagents}

All the cell lines (Me1007, Me4405, Me10538, Me2211M2, MDAMB231) were maintained in RPMI plus $10 \%$ fetal calf serum. Bortezomib (Velcade) was kindly provided by Professor Carlostella, isoleucine zipper (iz)-TRAIL was produced as described (Ganten et al, 2006). SMAC-mimetics were synthesised at the CISI Institute. The primary antibodies were purchased from Cell Signaling Technology (Beverly, MA, USA) (cleaved caspase-3 and cleaved PARP), Alexis Biochemicals (San Diego, CA, USA) (cFLIP, caspase-8), BD Biosciences (San Jose, CA, USA) (XIAP and cIAP2), Sigma (St Louis, MO, USA) ( $\beta$-Actin) and R\&D Systems (Minneapolis, MN, USA) (cIAP1). ECL-HRP linked secondary antibodies were from GE Healthcare (Piscataway, NJ, USA). siCASP8 SMARTpool was purchased from Dharmacon (Lafayette, CO, USA), z-vad-fmk from BIOMOL Int (Plymouth Meeting, PA, USA).

\section{Cell proliferation and apoptosis}

Cell proliferation was determined by the MTT assays on cells seeded in 96-well culture plates (10000 cells per well) with $100 \mu \mathrm{l}$ of medium, treated $24 \mathrm{~h}$ later with drugs and incubated for further $72 \mathrm{~h}$. MTT absorbance was read with a plate reader (Tecan Genios, Tecan US, Durham, NC, USA) at a wavelength of $495 \mathrm{~nm}$. The blank value was subtracted from each measurement and the percentage of viability was determined by comparison with untreated cells. Apoptotic cells with a sub-diploid G1 content were quantitated by flow cytometry on samples that after treatment with drugs, were harvested, fixed in $70 \%$ ethanol, treated with RNAse and stained with propidiun iodide. Sub-G1 population was then revealed with a FACS-Scan (Becton Dickinson, San Jose, CA, USA).

\section{Western blot analysis}

Cells were lysed in SDS/Tris-HCl and fractionated on SDS-PAGE. Proteins were blotted on PVDF membranes, saturated with non-fat dry milk and incubated overnight with the indicated primary antibody. After washing, the membranes were exposed to the appropriate secondary antibody for $1 \mathrm{~h}$ and finally the proteins of interest were detected by ECL (Pierce, Rockford, IL, USA).

\section{Recombinant protein purification}

pET28 XIAP-Bir3 and XIAP-lkBir2Bir3 were used to produce the recombinant proteins for the binding assay (Mastrangelo et al, 2008). The plasmids were used to transform Escherichia coli strain BL21(DE3) and induced with $1 \mathrm{~mm}$ of IPTG. Bacteria grown in LB medium plus kanamycin and $50 \mu \mathrm{m}$ zinc acetate were harvested, resuspended in a buffer containing $50 \mathrm{~mm}$ Tris- $\mathrm{HCl}, \mathrm{pH} \mathrm{7.5,}$ $200 \mathrm{mM} \mathrm{NaCl}$ and protease inhibitors, treated with $100 \mu \mathrm{g} \mathrm{ml}^{-1}$ lysozyme for $30 \mathrm{~min}$ on ice, and then lysed by sonication. After elimination of debris by centrifugation, recombinant protein was purified using Ni-NTA (His-trap FFcrude, GE Healthcare), followed by gel filtration (Superdex 200, GE Healthcare). The recombinant proteins were eluted with $250 \mathrm{~mm}$ imidazole and thereafter stored in $20 \mathrm{~mm}$ Tris, $\mathrm{pH} 7.5,200 \mathrm{~mm} \mathrm{NaCl}$ and 10 mM DTT.

\section{Binding assays}

Fluorescent polarisation-based binding assay was performed as described before (Mastrangelo et al, 2008; Cossu et al, 2009b). Briefly, two saturation curves were obtained by adding increasing concentrations of recombinant XIAP-BIR3 (241-356) or XIAPlkBIR2BIR3 (124-356) to a fixed quantity of a fluorescent monomeric or dimeric SMAC-mimetic, respectively. The $\mathrm{Kd}$ was measured and used to determine the concentration of probe to be used in the competition experiment, in which SMAC-mimetics were added at rising concentrations. All data were plotted using Graphpad (San Diego, CA, USA).

\section{XIAP knock-down}

XIAP knock-down was obtained by RNA interference using lentiviral vectors (Invitrogen, Carlsbad, CA, USA). Lentiviruses were produced in accordance to the manufacturer's instructions. In all, 293FT cells were transfected with ViraPower (Invitrogen) plus a pLenti vector carrying a sequence for XIAP RNA interference (Kashkar et al, 2007) or a control sequence (shLac), using Lipofectamine2000 (Invitrogen). The following day the medium was substituted and then collected after $24 \mathrm{~h}$, clarified from cellular debris by centrifugation and added to the cells of interest. Transduced clones were selected by adding blasticidin to a final concentration of $6 \mu \mathrm{g} \mathrm{ml}^{-1}$.

\section{Synthesis of SMAC-mimetics}

The synthesis of monomeric SMAC067 has already been reported by us (Seneci et al, 2009), while the synthesis of the dimeric 
compounds SMAC074, SMAC075 and SMAC076 (Supplementary Figure S2) will be reported in a forthcoming paper (P Seneci, C Battaglia, L Belvisi, M Bolognesi, A Caprini, F Cossu, M de Matteo, D Delia, C Drago, D Lecis, L Manzoni, M Marizzoni, E Mastrangelo, M Milani, E Moroni, D Potenza, V Rizzo, F Servida, F Vasile and C Scolastico, 2010, to be submitted).

\section{RESULTS}

\section{TRAIL sensitivity in melanoma cell lines}

We evaluated the sensitivity of the well-characterised melanoma cell lines Me4405, Me10538, Me2211M2 and Me1007 derived from patients of our institute, to increasing concentrations of iz-TRAIL. The proliferation of Me4405, Me10538 and Me2211M2 was inhibited by TRAIL in a dose-dependent manner, while Me1007 cells were resistant to this drug (Supplementary Figure S1) in keeping with the their low expression of caspase-8 (Zhang et al, 2001), a key mediator of the extrinsic apoptosis pathway (Chen et al, 2008). TRAIL-induced apoptosis was accompanied by cleavage of PARP, strongly detectable in all the lines except Me1007 (Figure 1), and by activation of caspase- 8 yielding the cleaved p41 and 43 forms. These two bands were undetectable in Me1007 but evident in the other cell lines, and accompanied by the reduction of full-length caspase- 8 (Figure 1). Caspase- 8 cleaves and activates the effector caspase-3, whose cleaved forms were detectable in all lines tested after treatment with iz-TRAIL. We also analysed the response to Bortezomib and compound-3, a dimeric SMAC-mimetic (Li et al, 2004), but these agents had little effect, if any, in activating apoptosis at the doses used (Figure 1). Altogether, iz-TRAIL kills melanoma cells by activating the extrinsic apoptosis pathway involving caspase- $8,-3$ and PARP cleavage. This pathway is associated with caspase-8, whose faint levels in Me1007 preclude their responsiveness.
Downregulation of XIAP is sufficient to restore TRAIL sensitivity even in melanoma cells with low expression of caspase-8

As sensitisation of tumour cells to TRAIL can be achieved by downregulating XIAP (Vogler et al, 2008), we asked whether a similar response could be induced in Me1007 cells, in spite of their low expression of caspase-8. We therefore generated Me1007 cells stably expressing an shRNA-targeting XIAP or a control sequence (shLac) as negative control. Interestingly, XIAP knock-down restored TRAIL sensitivity in Me1007 (Figure 2A) and this was not cell-type specific because a similar phenomenon was observed in the mammary carcinoma cell line MDA-MB231 (Figure 2B). The treatment with $50 \mathrm{ng} \mathrm{ml}^{-1}$ iz-TRAIL for $24 \mathrm{~h}$ resulted in the accumulation of the p43/41 form of caspase- 8 in MDA-MB231 (Figure 2C right) but not in Me1007 cells (Figure 2C left). Furthermore, this accumulation was evident in cells with downregulated levels of XIAP and not in control cells expressing the scrambled sequence (shLac, Figure 2C right). Interestingly, TRAIL treatment induced the downregulation of XIAP also in control cells. Cleaved caspase-8 was detectable in Me1007 cells after $6 \mathrm{~h}$ of treatment only in response to doses of iz-TRAIL $\geqslant 1 \mu \mathrm{g} \mathrm{ml}^{-1}$, and even so the p43/41 form was evident only in cells with downregulated levels of XIAP (Figure 2D).

Thus, XIAP contributes to the resistance of melanoma cells to TRAIL and its downregulation favours the extrinsic apoptotic pathway.

\section{Bortezomib sensitises melanoma cells without affecting caspase-8 expression levels}

The proteasome inhibitor Bortezomib (Velcade/PS-341) is an effective drug in the treatment of multiple myeloma and other
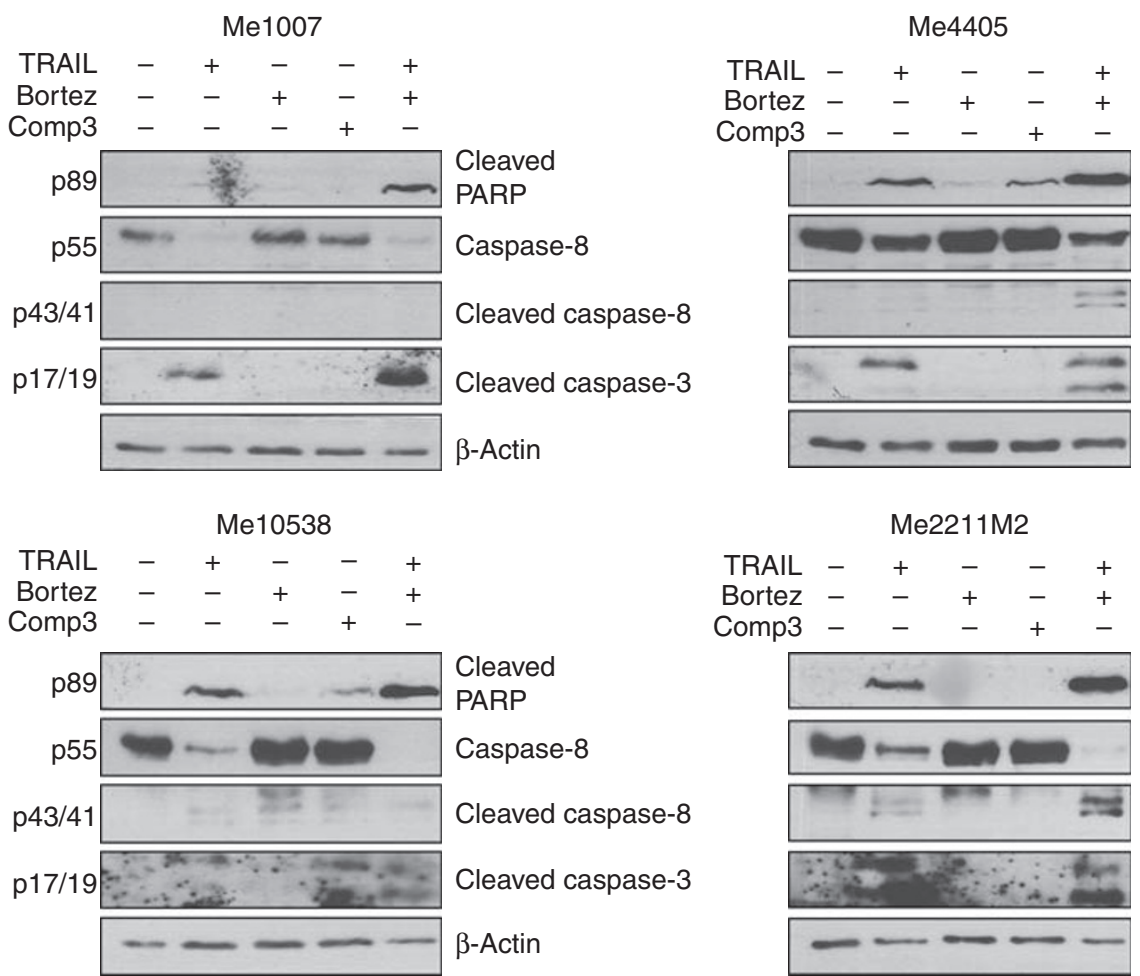

Figure I Sensitivity of melanoma cell lines to TRAIL, Bortezomib and SMAC-mimetics. Levels of cleaved PARP, caspase-3, caspase-8 or full-length caspase-8 in melanoma cells treated for $24 \mathrm{~h}$ with $50 \mathrm{ng} \mathrm{ml}^{-1}$ iz-TRAlL, $5 \mathrm{~nm}$ Bortezomib (4 nM in the case of Mel007) or $500 \mathrm{~nm}$ compound 3 or mocktreated. $\beta$-Actin is used as loading control. 

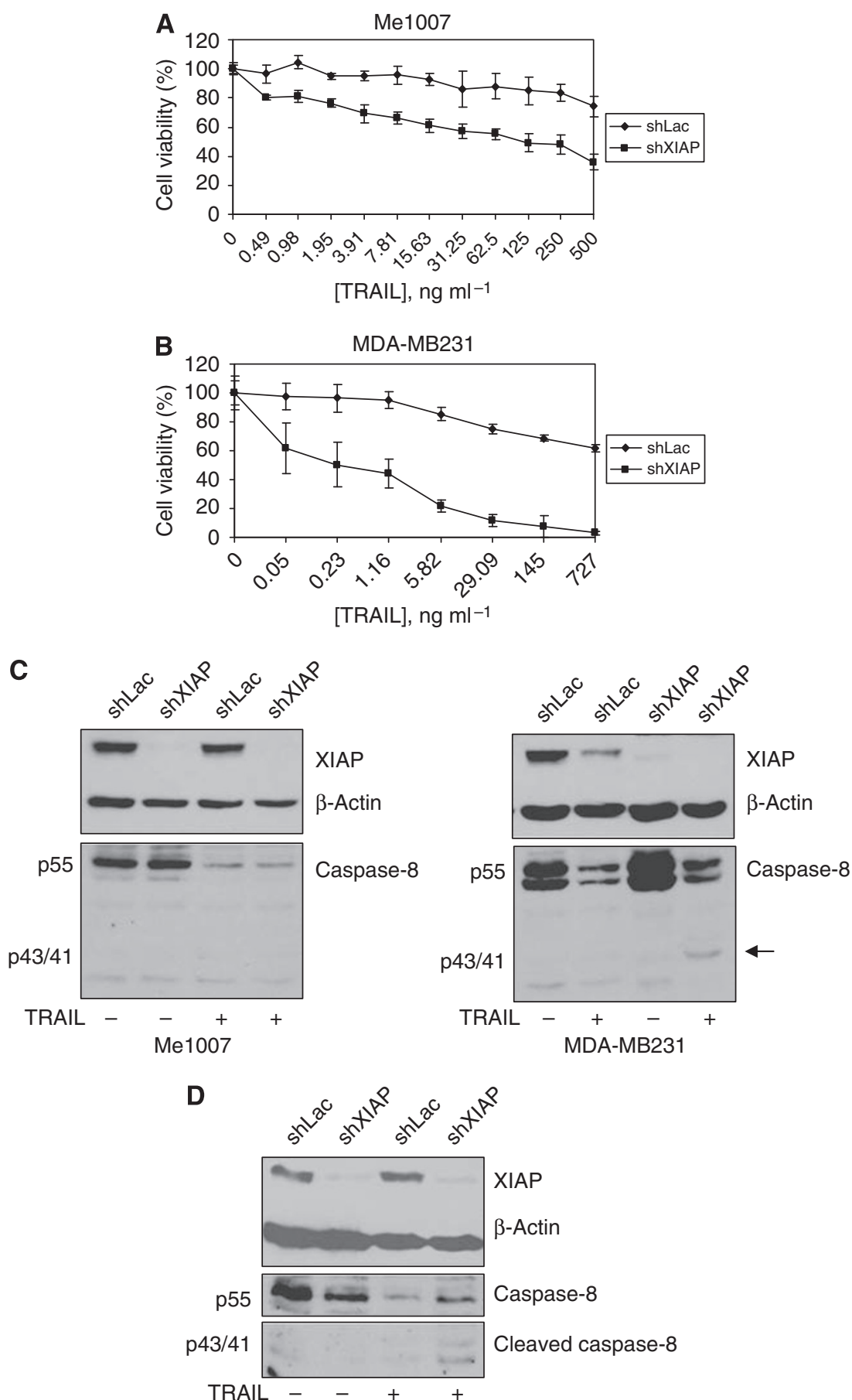

Figure 2 Role of XIAP in TRAIL resistance. Isogenic Mel007 (A) or MDA-MB23I (B) cell lines with normal (shLac) or downregulated levels of XIAP were treated with serial dilutions of iz-TRAIL. Cell proliferation was measured after $72 \mathrm{~h}$ by MTT assay. The figure is representative of three independent experiments carried out in triplicate (mean values \pm s.d.). (C) Levels of cleaved or full-length caspase-8 in Mel007 (left) or MDA-MB23I (right) with knockdown or normal levels of XIAP, treated or untreated with $50 \mathrm{ng} \mathrm{ml}^{-1}$ for $24 \mathrm{~h}$. Arrow indicates the p43/4I forms of caspase-8. $\beta$-Actin is used as loading

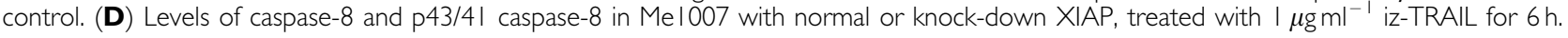

tumours, mainly functioning by inhibition of the NF- $\kappa \mathrm{B}$ survival pathway (reviewed by Boccadoro (Boccadoro et al, 2005)). Besides, it sensitises tumour cells to other agents, including TRAIL (Koschny et al, 2007). To determine whether Bortezomib potentiates the activity of TRAIL also in melanoma cells, we first tested it alone and found that at $4-5 \mathrm{~nm}$ it inhibits the growth of all melanoma cell lines. Significantly, the combination of TRAIL with Bortezomib markedly increased loss of cell viability in all melanoma lines (Figure 3A), paralleled by a rise in cleaved PARP (Figure 1).

Two inducers of endoplasmic reticulum (ER) stress, Thapsigargin and Tunicamycin, have been suggested to sensitise Me1007 to TRAIL by upregulation of TRAIL-R2 (Chen et al, 2007; Jiang et al, 2007) and caspase- 8 (Chen et al, 2008). As Bortezomib can also cause ER stress (Boccadoro et al, 2005), we checked whether it upregulated caspase- 8 in Me1007, but no evidence for this was 

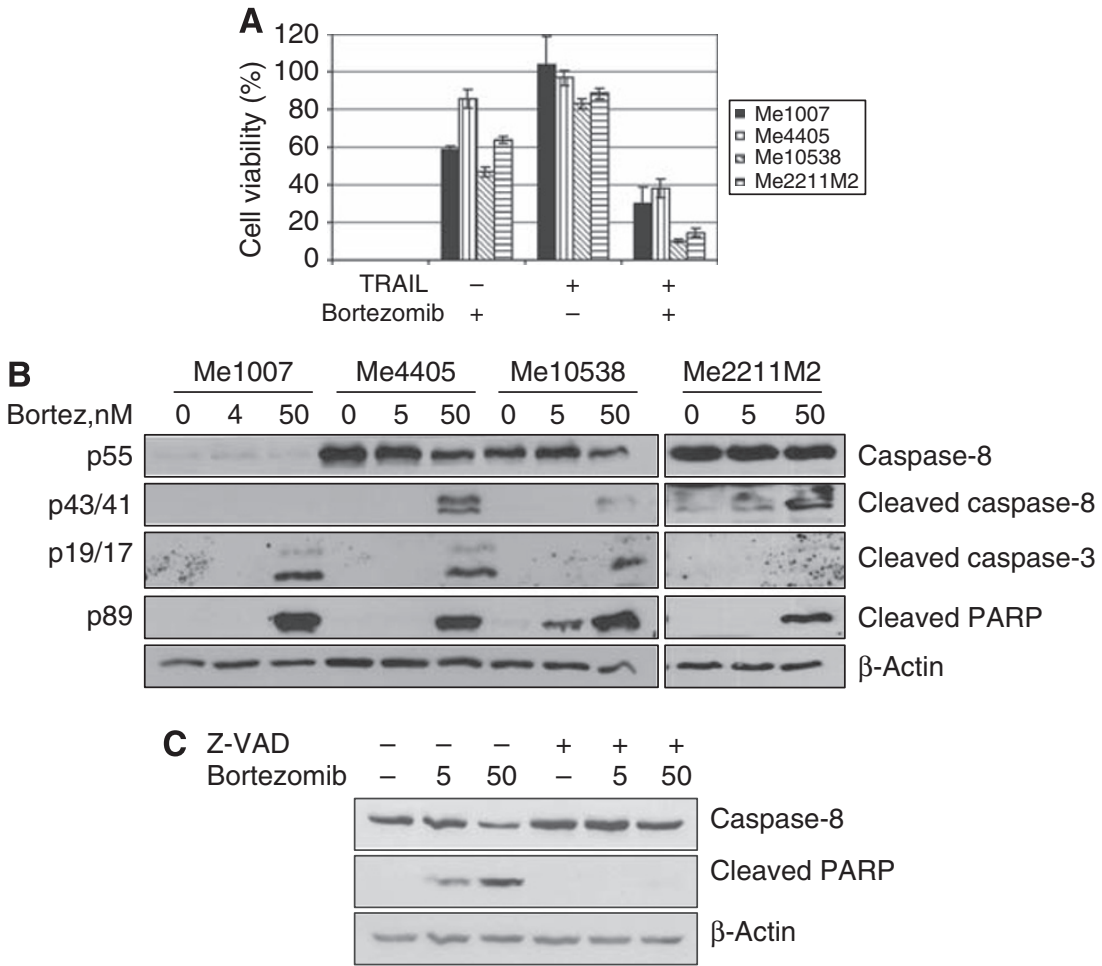

Figure 3 Bortezomib sensitises melanoma cells to TRAlL without affecting caspase-8 levels. (A) Cell proliferation evaluated $72 \mathrm{~h}$ after treatment with $5 \mathrm{~nm}$ Bortezomib ( $4 \mathrm{~nm}$ for Mel007) or $50 \mathrm{ng} \mathrm{ml}^{-1}$ of iz-TRAlL or a combination thereof (MTT assay). The figure is representative of three independent experiments carried out in triplicate (mean values \pm s.d.). (B) Levels of full-length caspase- 8 or cleaved PARP, caspase- 8 and -3 in lysates from melanoma cell lines treated with Bortezomib for $24 \mathrm{~h}$ at the indicated doses. (C) Levels of caspase-8 in lysates of Mel 007 treated with Bortezomib for $24 \mathrm{~h}$ at the indicated doses (nM) and/or pretreated for I h with I5 $\mu \mathrm{M}$ of z-VAD-fmk. Determination of PARP cleavage was used as a control to check activity of z-VAD-fmk and $\beta$-Actin served as loading control.

observed, even in response to elevated doses of Bortezomib (Figure 3B). As the accumulation of procaspase- 8 could be masked by its concomitant cleavage into the active forms, cells were pretreated with the pan caspase inhibitor z-VAD-fmk, which blocks caspase- 8 cleavage. The treatment prevented caspase activation, as revealed by inhibition of PARP cleavage (Figure 3C), but did not affect the levels of caspase-8. Interestingly, treatment with Bortezomib at a concentration of $50 \mathrm{nM}$ caused the accumulation of the p43/41 form of caspase- 8 (Figure 3B). Altogether, these findings show that Bortezomib sensitises melanoma lines to TRAIL without affecting the caspase- 8 levels.

\section{New SMAC-mimetics targeting the BIR2 and BIR3 domains of XIAP}

Recently, we have described a group of 4-substituted azabicyclo [5.3.0] alkane SMAC-mimetics with submicromolar binding affinity for XIAP. We showed that the introduction of a new chemical arm in position 4 actually favoured the establishment of new interactions between the SMAC-mimetics and the BIR domains of XIAP (Mastrangelo et al, 2008; Cossu et al, 2009a), strengthening the binding of our compounds to the target protein. The SMACmimetic molecules were first modified by the introduction of a $\mathrm{N}$-terminal methyl group to improve the cellular permeability (Sun et al, 2006), yielding SMAC067 (compound 4b, (Seneci et al, 2009)). As dimeric SMAC-mimetics have been shown to be more potent than their monomeric counterparts in activating apoptosis (Li et al, 2004), we synthesised three homodimeric compounds by coupling two SMAC067 units with different linkers (Supplementary Figure S2). The affinity of the compounds for XIAP BIR3 and lkBIR2/BIR3, measured by fluorescent polarisation as described (Nikolovska-Coleska et al, 2004, 2008) revealed that all three
Table I Affinities of newly developed SMAC-mimetics for XIAP BIR3 and IkBIR2BIR3

\begin{tabular}{lcc}
\hline Compound & IC $_{\mathbf{5 0}}$ BIR3 \pm s.e.\% $\mathbf{~ M M}$ & IC $_{\mathbf{5 0}} \mathbf{~ I k B I R 2 3} \pm$ s.e.\% $\mathbf{~ n M}$ \\
\hline $67^{\mathrm{a}}$ & $104 \pm 14.2$ & $54 \pm 48.5$ \\
74 & $180.5 \pm 13.2$ & $5.91 \pm 22.2$ \\
75 & $178.8 \pm 15.9$ & $3.18 \pm 18.4$ \\
76 & $157 \pm 13.5$ & $2.27 \pm 24.5$ \\
\hline
\end{tabular}

Abbreviations: $\mathrm{BIR}=$ baculoviral inhibitor repeats; $\mathrm{SMAC}=$ second mitochondriaderived activator of caspase; s.e.\% = standard error \%; XIAP $=$ X-linked inhibitor of apoptosis protein. The affinities of the new SMAC-mimetic compounds were evaluated by a fluorescent polarisation-based binding assay using increasing concentrations of SMAC-mimetics, two fluorescent dyes and the recombinant proteins containing the BIR3 or the IkBIR2BIR3 domains of XIAP as described in Material and Methods. ${ }^{a}$ See Seneci et al (2009).

dimeric compounds had a lower affinity for BIR3 than the monomers (Table 1), suggesting that the linker region slightly hinders the interaction with BIR3 in vitro. However, the interaction of the homodimers with the lkBIR2/BIR3 was 10-fold higher compared with the monomer. Little differences in affinity could be detected between the three bivalent compounds towards BIR3 or lkBIR2/BIR3, with SMAC076 being the best interactor of both recombinant proteins.

Aside from XIAP, SMAC-mimetics have been shown also to bind cIAP1 and cIAP2 (Varfolomeev et al, 2007; Vince et al, 2007). However, in contrast to XIAP, the binding of SMAC-mimetics to cIAPs induces their rapid auto-ubiquitination and subsequent proteasomal degradation. To determine whether the newly developed SMAC-mimetics caused the degradation of cIAP1 and 


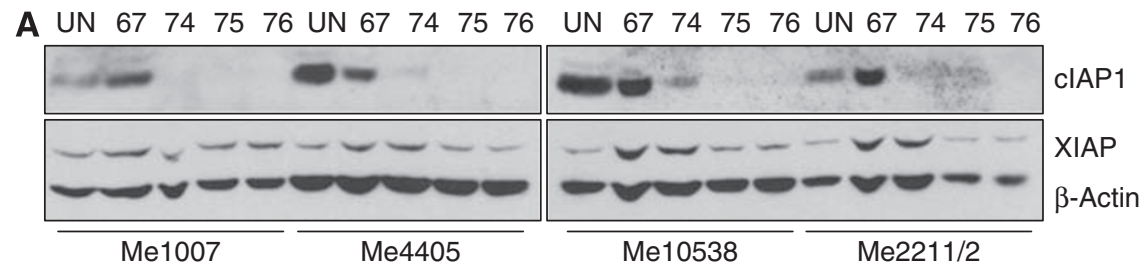

B UN 67747576 UN 67747576

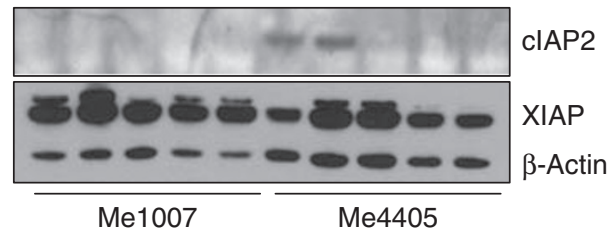

Figure 4 New SMAC-mimetics targeting IAPs. (A) Levels of CIAPI and XIAP in melanoma cell lines treated for $3 \mathrm{~h}$ with $500 \mathrm{nM}$ of the indicated compounds or mock-treated (UN). (B) Levels of cIAP2 and XIAP in melanoma cell lines treated for $3 \mathrm{~h}$ with $500 \mathrm{nM}$ of the indicated compounds or mocktreated (UN). $\beta$-Actin served as loading control.

cIAP2, we treated the four melanoma cell lines with the monomeric or dimeric SMAC-mimetics and analysed the effect of treatment on cIAP1/2 expression. Interestingly, all three dimeric compounds decreased the levels of cIAP1 and cIAP2 (Figures 4A and B and data not shown), most effectively in response to SMAC075 and SMAC076. SMAC067, on the contrary, had little effect, if any, on cIAP1 and cIAP2 levels. It is noteworthy that Me1007 cells were negative for the expression of cIAP2 (Figure 4B). Altogether, our new SMAC-mimetics not only bind XIAP with nanomolar affinities, but also induce the intracellular degradation of cIAP1 and CIAP2.

\section{SMAC-mimetics synergise with TRAIL}

The in vitro synergism of SMAC-mimetics with TRAIL underscores the potential of this combination in cancer treatment ( $\mathrm{Li}$ et al, 2004; Vogler et al, 2009). As a result of this, we analysed the synergism of TRAIL with our SMAC-mimetics more thoroughly. At the doses used here as single agents TRAIL and SMAC-mimetics had little effect on viability. However, in combination they potently induced loss of cell viability in all cell lines tested, except Me1007 (Figure 5A). This was associated with a strong activation of the apoptotic pathway, involving cleavage of caspase-8, activation of caspase- 3 and accumulation of cleaved PARP (Figure 5B). Thus, cell death was due to apoptosis as this event was also abrogated by pretreatment with the pan-caspase inhibitor z-VAD-fmk (Figure 5A). Apoptosis was modest in Me1007, disappearance of full-length caspase- 8 was not accompanied by accumulation of detectable p $41 / \mathrm{p} 43$ of caspase- 8 (Figure 5B). Nevertheless, a faint band of cleaved PARP appeared, suggesting that at least in some cells effector caspase activation had occurred. Western blot analysis confirmed the potent apoptogenic effect of iz-TRAIL in combination with SMAC-mimetics as compared with the single agents, and that the dimeric SMAC-mimetics are more powerful than the monomeric one in synergising with TRAIL (Figure 5B). Apoptotic cells were also assessed by flow cytometry analysis of the sub-G1 peak. The combined treatment of TRAIL with a SMACmimetic (SMAC075) augmented the proportion of the sub-diploid apoptotic population compared with single and mock treatments (Supplementary Table S3 and data not shown) in melanoma cells responsive to these drugs, while the increment was modest in Me1007.

It is noteworthy that the diverse linkers used have little effect on SMAC-mimetic activity, in accordance with the affinity for XIAP in vitro (Table 1) or stimulation of cIAP1/2 degradation (Figures $4 \mathrm{~A}$ and $\mathrm{B}$ ). Hence, our new SMAC-mimetics are able to inhibit melanoma cell growth by inducing apoptosis in synergism with iz-TRAIL.

\section{Bortezomib synergises with SMAC-mimetics in melanoma cell lines resistant to the combined effect of TRAIL/ SMAC-mimetic}

As Bortezomib sensitises cells to TRAIL-induced apoptosis at a different level than SMAC-mimetics, namely at the TRAIL DISC, we next addressed whether their combination would be synergistic in sensitising melanoma cells to TRAIL-induced apoptosis. We first tested the Me1007 cell line, which is poorly responsive to the TRAIL/SMAC-mimetics (Figure 5A), and found that already the combination of Bortezomib with dimeric SMAC-mimetics, induced almost complete loss of cell viability (Figure 6A). By contrast, the single compounds showed little activity (Figures 5A and $6 \mathrm{~A}$ ). The loss of cell viability by Bortezomib and SMACmimetics was due to apoptosis as it was accompanied by the accumulation of cleaved caspase- 3 and PARP (Figure 6B), and to some extent dependent on caspase- 8 because its depletion rescued cells from death triggered by Bortezomib (data not shown). Conversely, the cell lines sensitive to TRAIL/SMAC-mimetic were less sensitive to Bortezomib/SMAC-mimetic combination (Figure 6C and data not shown). As Bortezomib has been shown to be capable of modulating the expression levels of different proteins involved in regulating sensitivity to TRAIL (Koschny et al, 2007), we checked the expression of the caspase-8 inhibitor cFLIP. However, neither Bortezomib nor the SMAC-mimetics or their combinations affected cFLIP expression (Figure 6B).

These findings indicate that in vitro melanoma cells resistant to the combination of TRAIL with SMAC-mimetics can be killed by the combined effects of Bortezomib and SMAC-mimetic. Thus, the combination of SMAC-mimetics with Bortezomib, previously shown to kill multiple myeloma cells in vitro (Chauhan et al, 2007), may also be useful for the treatment of melanoma.

\section{DISCUSSION}

$\mathrm{X}$-linked IAP is a pivotal anti-apoptotic regulator, owing to its capacity to bind and block both initiator and effector caspases (Deveraux et al, 1997). XIAP is overexpressed in many tumours in which it confers resistance to chemotherapeutic agents ( $\mathrm{Li}$ et al, 2004; Oost et al, 2004) and to TRAIL, an apoptosis-inducing biotherapeutic drug (Walczak et al, 1999) currently tested in various clinical trials (Ashkenazi and Herbst, 2008; Newsom-Davis 
A
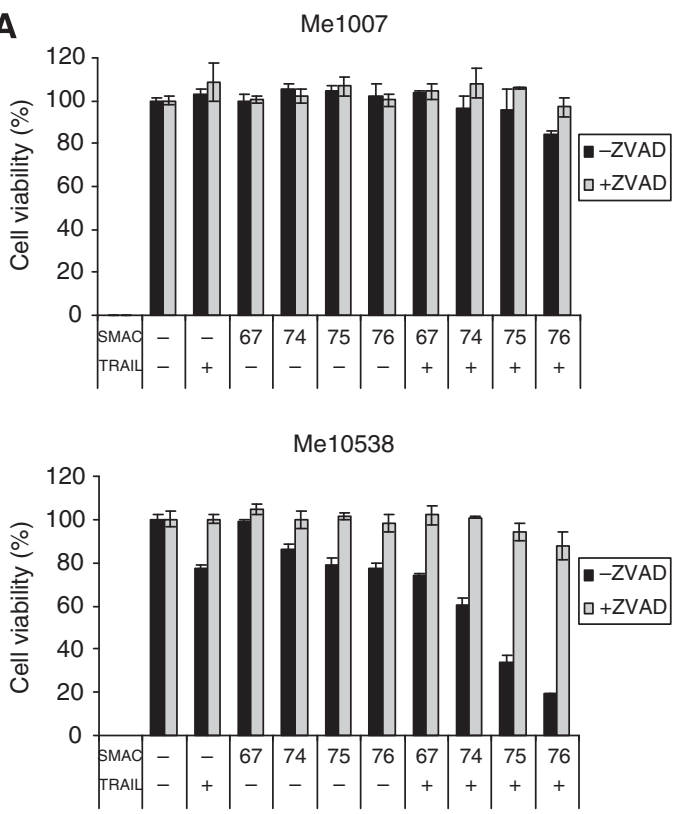

B

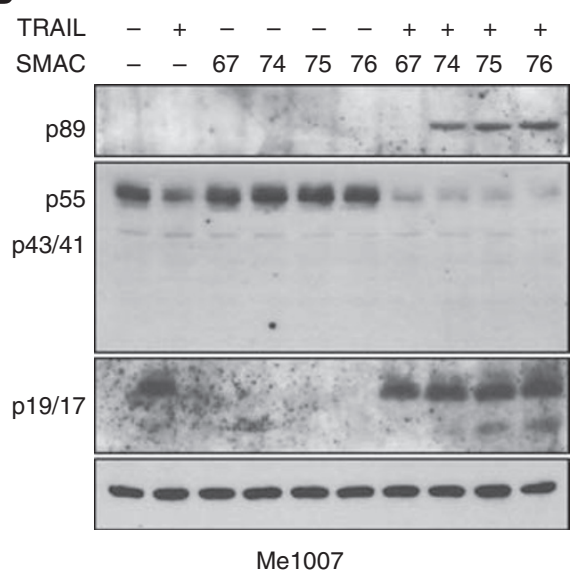

TRAIL - + $-\quad-\quad-++++$

SMAC - - $67 \quad 747576 \quad 67747576$

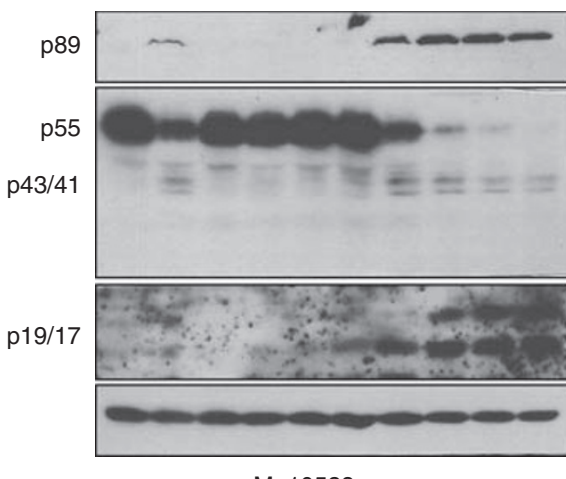

$\beta$-Actin

PARP

$\beta$-Actin
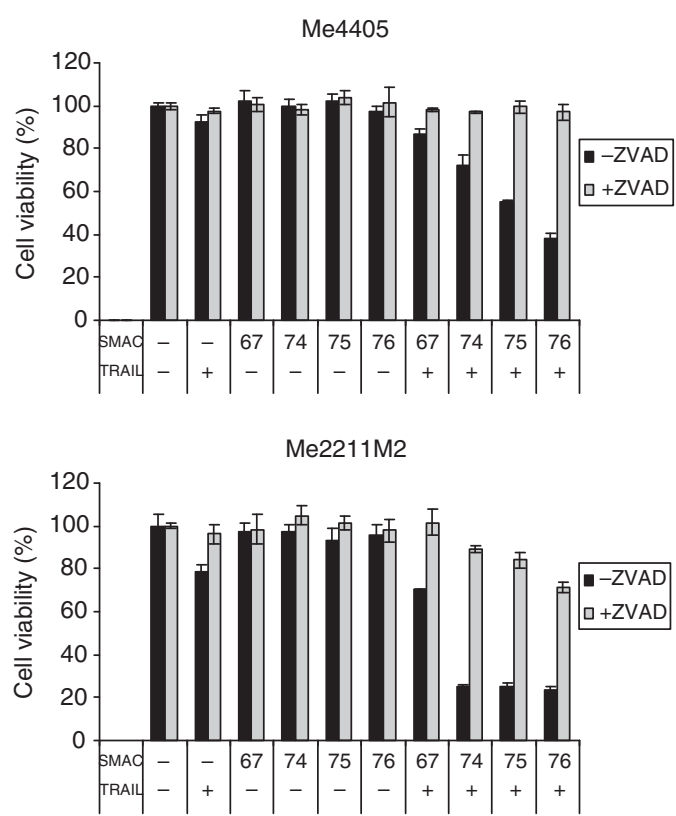

TRAIL

SMAC

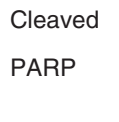

Caspase-8

Cleaved

Caspase-3

TRAIL

Cleaved

Caspase-8

Cleaved

Caspase-3

Me10538

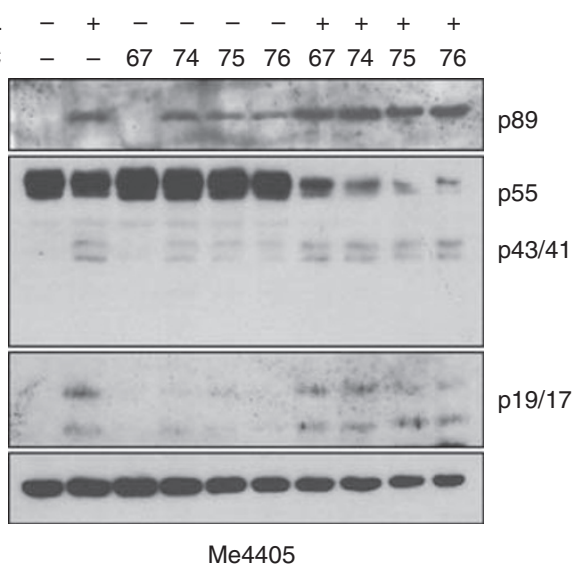

$\mathrm{p} 19 / 17$

SMAC
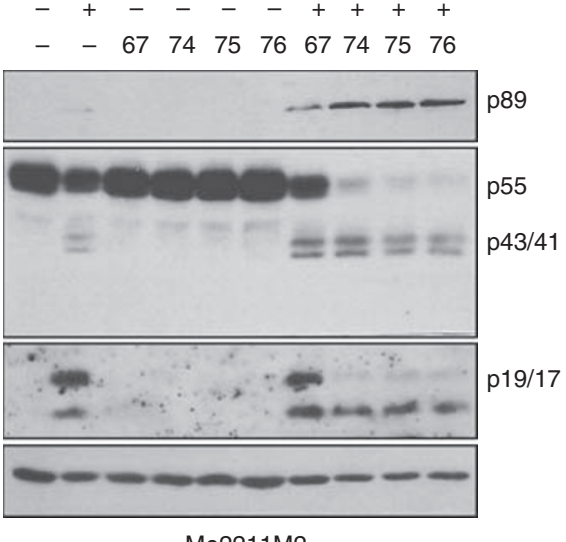

$\mathrm{Me} 2211 \mathrm{M} 2$

Figure 5 SMAC-mimetics synergise with TRAIL in triggering apoptosis. (A) Cell viability was evaluated $72 \mathrm{~h}$ after onset of treatment with $500 \mathrm{nM}$ SMAC-mimetic and/or iz-TRAIL used at $50 \mathrm{ng} \mathrm{ml}^{-1}$ with or without pretreatment with $15 \mu \mathrm{M}$ of z-vad-fmk (MTT assay). The figure is representative of three independent experiments carried out in triplicate (mean values \pm s.d.). (B) Levels of caspase-8, cleaved PARP and caspase-3 in cells treated for $24 \mathrm{~h}$ with iz-TRAIL at $50 \mathrm{ng} \mathrm{ml}^{-1}$ and SMAC-mimetic at $500 \mathrm{~nm}$. $\beta$-Actin served as loading control.

et al, 2009). Unlike the other apoptosis-inducing ligands of the TNF superfamily, TNF and CD95L, TRAIL is not toxic for normal cells, suggesting its potential exploitability for treatment purposes.
In spite of the fact that different members of the IAP family show high homology and can have redundant roles, nevertheless XIAP is so far the only member known to affect sensitivity to 


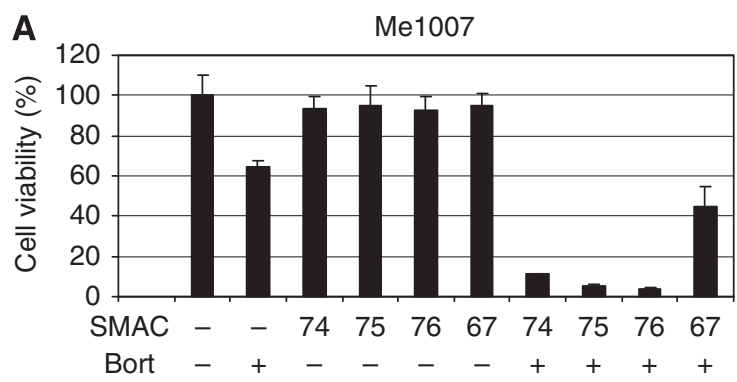

\section{B}
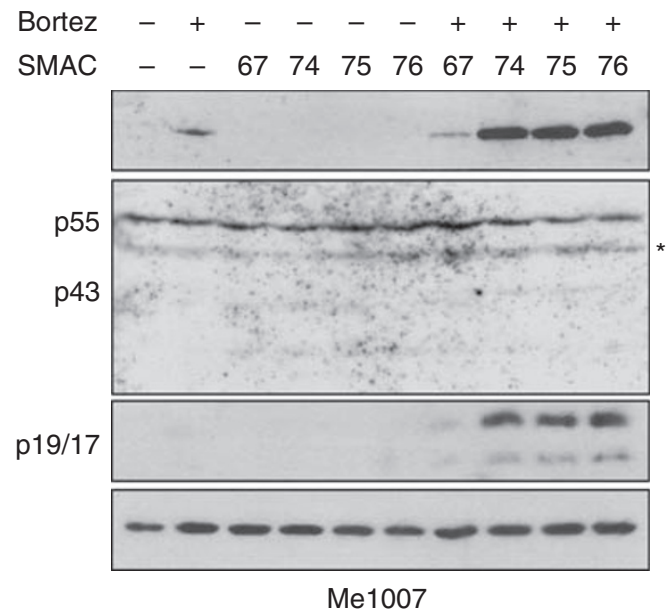

Cleaved PARP

Cleaved

Caspase-3

$\beta$-Actin

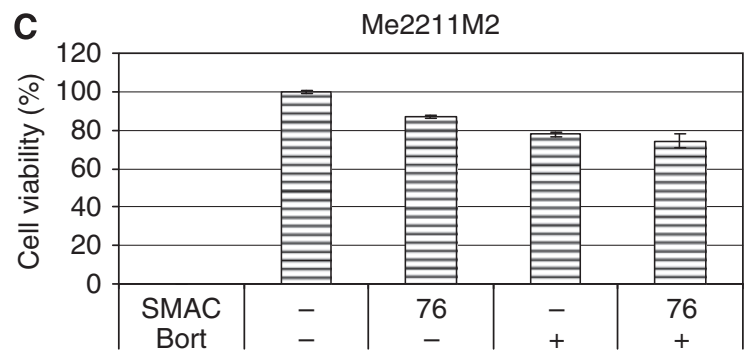

Figure 6 SMAC-mimetics synergise with Bortezomib in triggering apoptosis in Mel007 cells. (A) Mel007 cell viability was evaluated $72 \mathrm{~h}$ after treatment with $500 \mathrm{nM}$ SMAC-mimetic and/or Bortezomib $4 \mathrm{nM}$ (MTT assay). The figure is representative of three independent experiments in triplicate (mean values \pm s.d.). (B) Levels of cleaved PARP and caspase-3, and cFLIP in cells treated for $24 \mathrm{~h}$ with Bortezomib at $4 \mathrm{nM}$ and SMACmimetics at $500 \mathrm{nM}$. $\beta$-Actin served as loading control. The asterisk indicates a nonspecific band. (C) Me22I IM2 cell viability was evaluated $72 \mathrm{~h}$ after treatment with $500 \mathrm{nM}$ SMAC076 and/or Bortezomib $5 \mathrm{nM}$ (MTT assay). The figure is representative of two independent experiments carried out in triplicate (mean values \pm s.d.)

TRAIL-induced apoptosis (Cummins et al, 2004), providing a rationale for combining TRAIL with drugs targeting XIAP.

In our work, we first treated some melanoma cell lines with iz-TRAIL, a recombinant TRAIL fused with a synthetic isoleucine zipper that favours trimerisation, thereby enhancing its activity (Ganten et al, 2006), a phenomenon we had first reported for a different version of TRAIL together with an in vivo half-life of approximately $1 \mathrm{~h}$ (Walczak et al, 1997). Together, increased activity because of stable trimer formation and increased half-life renders isoleucine zipper tagged forms of TRAIL potentially better drug candidates as we previously showed (Walczak et al, 1999; Ganten et al, 2004, 2006) and has recently been confirmed by others (Rozanov et al, 2009). Three melanoma lines were sensitive to iz-TRAIL at high concentrations but their response could be amplified by concomitant administration of SMAC-mimetics. By contrast and in concordance with a previous report (Zhang et al, 2001), the fourth line tested, Me1007, was resistant to iz-TRAIL treatment, most likely because of caspase- 8 expression being too low to enable activation of the extrinsic apoptosis pathway. Interestingly, the knock-down of XIAP and, partially, the simultaneous administration of the new SMAC-mimetic compounds we developed, could restore sensitivity of Me1007 cells to TRAIL-induced apoptosis. In these cells, low levels of caspase- 8 could probably activate little caspase- 3 that XIAP keeps in check preventing the apoptosis cascade, but when XIAP is targeted, the levels of caspase- 3 might become enough to trigger apoptosis.

Interestingly, in presence of downregulated levels of XIAP, there is an accumulation of the cleaved p43 and p41 forms of caspase-8, both in melanoma and mammary carcinoma cell lines. XIAP could influence this event in two ways, directly by ubiquitinating the cleaved form of caspase- 8 and causing its degradation, or indirectly by blocking caspase-3, which was previously shown to cleave caspase-8 (Wieder et al, 2001; Lee et al, 2005; Hayakawa et al, 2008). As XIAP was shown to interact with caspases 3, 7 and 9 , but not 8 (Deveraux et al, 1998), it is unlikely that the accumulation of the p43/41 forms of caspase- 8 is caused directly by XIAP. More likely, XIAP, by inhibiting caspase-3, prevents its positive feedback loop, by which caspase- 8 is further cleaved (Wieder et al, 2001; Lee et al, 2005; Hayakawa et al, 2008). Thus, lower levels of XIAP allow the accumulation of the cleaved form of caspase-8.

SMAC-mimetics have been shown to activate apoptosis also as stand-alones in a few cell lines (Petersen et al, 2007). This mechanism is independent from their activity on XIAP, and rather because of their capacity of targeting cIAP1 and cIAP2 (Varfolomeev et al, 2007; Vince et al, 2007). In this case, SMAC-mimetics do not trigger apoptosis by displacing caspases from XIAP, but by inducing TNF and rendering cancer cells sensitive to autocrine TNF $\alpha$ (Varfolomeev et al, 2007; Vince et al, 2007; Bertrand et al, 2008). According to this, the apoptotic pathway depends on caspase- 8 presence, but is not influenced by XIAP levels (Gaither et al, 2007). Indeed, the new dimeric SMAC-mimetics we present here are able to trigger rapid and complete degradation of cIAP1, and, consequently, to cause apoptosis in MDA-MB231 cells as single agents (data not shown).

Nevertheless, SMAC-mimetics are more widely utilisable in association with other drugs to favour their activity (Li et al, 2004). In this study, we show that the newly developed SMAC-mimetics can facilitate the apoptotic cascade stimulated by TRAIL, rendering melanoma cells, which are notoriously resistant to chemotherapy, more sensitive to this ligand. Interestingly, the Me1007 cell line, resistant to SMAC-mimetic/TRAIL, became extremely sensitive to the combination of SMAC-mimetics and Bortezomib, the latter widely used in cancer therapy. This observation raises the possibility that SMAC-mimetics could be useful in combination with diverse drugs.

In conclusion, SMAC-mimetics targeting members of the IAP family, especially XIAP, offer a new strategy for the treatment of chemotherapy-resistant melanomas, particularly when used in combination with other drugs like Bortezomib, TRAIL or TRAIL-R agonists.

\section{ACKNOWLEDGEMENTS}

This work was supported by grants of the Italian Association for Cancer Research (AIRC) and the Italian Ministry of Health (Progetto Ordinario Oncologia).

Supplementary Information accompanies the paper on British Journal of Cancer website (http://www.nature.com/bjc) 


\section{REFERENCES}

Ashkenazi A, Herbst RS (2008) To kill a tumor cell: the potential of proapoptotic receptor agonists. J Clin Invest 118: 1979-1990

Bertrand MJM, Milutinovic S, Dickson KM, Ho WC, Boudreault A, Durkin J, Gillard JW, Jaquith JB, Morris SJ, Barker PA (2008) cIAP1 and cIAP2 facilitate cancer cell survival by functioning as E3 ligases that promote RIP1 ubiquitination. Mol Cell 30: 689

Boccadoro M, Morgan G, Cavenagh J (2005) Preclinical evaluation of the proteasome inhibitor bortezomib in cancer therapy. Cancer Cell Int 5: 18

Chauhan D, Neri P, Velankar M, Podar K, Hideshima T, Fulciniti M, Tassone P, Raje N, Mitsiades C, Mitsiades N, Richardson P, Zawel L, Tran M, Munshi N, Anderson KC (2007) Targeting mitochondrial factor Smac/DIABLO as therapy for multiple myeloma (MM). Blood 109: $1220-1227$

Chen LH, Jiang CC, Kiejda KA, Wang YF, Thorne RF, Zhang XD, Hersey P (2007) Thapsigargin sensitizes human melanoma cells to TRAIL-induced apoptosis by up-regulation of TRAIL-R2 through the unfolded protein response. Carcinogenesis 28: 2328-2336

Chen LH, Jiang CC, Watts R, Thorne RF, Kiejda KA, Zhang XD, Hersey P (2008) Inhibition of endoplasmic reticulum stress-induced apoptosis of melanoma cells by the ARC protein. Cancer Res 68: 834-842

Cossu F, Mastrangelo E, Milani M, Sorrentino G, Lecis D, Delia D, Manzoni L, Seneci P, Scolastico C, Bolognesi M (2009a) Designing Smacmimetics as antagonists of XIAP, cIAP1, and cIAP2. Biochem Biophys Res Commun 378: 162

Cossu F, Milani M, Mastrangelo E, Vachette P, Servida F, Lecis D, Canevari G, Delia D, Drago C, Rizzo V, Manzoni L, Seneci P, Scolastico C, Bolognesi M (2009b) Structural bases for bivalent Smac-mimetics recognition in the IAP protein family. J Mol Biol 392: 630-644

Cummins JM, Kohli M, Rago C, Kinzler KW, Vogelstein B, Bunz F (2004) $\mathrm{X}$-linked inhibitor of apoptosis protein (XIAP) is a nonredundant modulator of tumor necrosis factor-related apoptosis-inducing ligand (TRAIL)- mediated apoptosis in human cancer cells. Cancer Res 64: 3006

Deveraux QL, Roy N, Stennicke HR, Van Arsdale T, Zhou Q, Srinivasula SM, Alnemri ES, Salvesen GS, Reed JC (1998) IAPs block apoptotic events induced by caspase- 8 and cytochrome $c$ by direct inhibition of distinct caspases. EMBO J 17: 2215-2223

Deveraux QL, Takahashi R, Salvesen GS, Reed JC (1997) X-linked IAP is a direct inhibitor of cell-death proteases. Nature 388: 300-304

Du C, Fang M, Li Y, Li L, Wang X (2000) Smac, a mitochondrial protein that promotes cytochrome $\mathrm{c}$ dependent caspase activation by eliminating IAP inhibition. Cell 102: $33-42$

Eckelman BP, Salvesen GS (2006) The human anti-apoptotic proteins cIAP1 and CIAP2 bind but do not inhibit caspases. J Biol Chem 281: 3254

Gaither A, Porter D, Yao Y, Borawski J, Yang G, Donovan J, Sage D, Slisz J, Tran M, Straub C, Ramsey T, Iourgenko V, Huang A, Chen Y, Schlegel R, Labow M, Fawell S, Sellers WR, Zawel L (2007) A Smac mimetic rescue screen reveals roles for inhibitor of apoptosis proteins in t. Cancer Res 67: 11493

Galbán S, Hwang C, Rumble JM, Oetjen KA, Wright CW, Boudreault A, Durkin J, Gillard JW, Jaquith JB, Morris SJ, Duckett CS (2009) Cytoprotective effects of IAPs revealed by a small molecule antagonist. Biochem J 417: $765-771$

Ganten TM, Haas TL, Sykora J, Stahl H, Sprick MR, Fas SC, Krueger A, Weigand MA, Grosse-Wilde A, Stremmel W, Krammer PH, Walczak H (2004) Enhanced caspase- 8 recruitment to and activation at the DISC is critical for sensitisation of human hepatocellular carcinoma cells to TRAIL-induced apoptosis by chemotherapeutic drugs. Cell Death Differ 11: S86-S96

Ganten TM, Koschny R, Sykora J, Schulze-Bergkamen H, Buchler P, Haas TL, Schader MB, Untergasser A, Stremmel W, Walczak H (2006) Preclinical differentiation between apparently safe and potentially hepatotoxic applications of TRAIL either alone or in combination with chemotherapeutic drugs. Clin Cancer Res 12: 2640

Hayakawa A, Kawamoto Y, Nakajima H, Sakai J, Takasawa R, Nakashima I, Magae J, Tanuma S (2008) Bid truncation mediated by caspases-3 and -9 in vinorelbine-induced apoptosis. Apoptosis 13: $523-530$

Jiang CC, Chen LH, Gillespie S, Kiejda KA, Mhaidat N, Wang YF, Thorne R, Zhang XD, Hersey P (2007) Tunicamycin sensitizes human melanoma cells to tumor necrosis factor-related apoptosis-inducing ligand-induced apoptosis by up-regulation of TRAIL-R2 via the unfolded protein response. Cancer Res 67: 5880

Kashkar H, Deggerich A, Seeger J, Yazdanpanah B, Wiegmann K, Haubert D, Pongratz C, Kronke M (2007) NF-I\{kappal\}B-independent down-regulation of XIAP by bortezomib sensitizes HL B cells against cytotoxic drugs. Blood 109: $3982-3988$

Kempkensteffen C, Hinz S, Christoph F, Köllermann J, Krause H, Schrader M, Schostak M, Miller K, Weikert S (2007) Expression parameters of the inhibitors of apoptosis cIAP1 and cIAP2 in renal cell carcinomas and their prognostic relevance. Int J Cancer 120: $1081-1086$

Koschny R, Holland H, Sykora J, Haas TL, Sprick MR, Ganten TM, Krupp W, Bauer M, Ahnert P, Meixensberger J, Walczak H (2007) Bortezomib sensitizes primary human astrocytoma cells of WHO grades I to IV for tumor necrosis factor-related apoptosis-inducing ligand-induced apoptosis. Clin Cancer Res 13: 3403 - 3412

Kurbanov BM, Fecker LF, Geilen CC, Sterry W, Eberle J (2006) Resistance of melanoma cells to TRAIL does not result from upregulation of antiapoptotic proteins by NF-[kappa]B but is related to downregulation of initiator caspases and DR4. Oncogene 26: 3364-3377

Kurbanov BM, Geilen CC, Fecker LF, Orfanos CE, Eberle J (2005) Efficient TRAIL-R1//DR4-mediated apoptosis in melanoma cells by tumor necrosis factor-related apoptosis-inducing ligand (TRAIL). J Investig Dermatol 125: 1010 - 1019

Lee SH, Kim YK, Kim CS, Seol SK, Kim J, Cho S, Song YL, Bartenschlager R, Jang SK (2005) E2 of hepatitis C virus inhibits apoptosis. J Immunol 175: $8226-8235$

Lejeune FJ, Rüegg C, Liénard D (1998) Clinical applications of TNF- $\alpha$ in cancer. Curr Opin Immunol 10: 573

Li L, Thomas RM, Suzuki H, De Brabander JK, Wang X, Harran PG (2004) A small molecule Smac mimic potentiates TRAIL- and TNF\{alpha\}mediated cell death. Science 305: $1471-1474$

Liu Z, Sun C, Olejniczak ET, Meadows RP, Betz SF, Oost T, Herrmann J, Wu JC, Fesik SW (2000) Structural basis for binding of Smac/DIABLO to the XIAP BIR3 domain. Nature 408: $1004-1008$

Lu J, Bai L, Sun H, Nikolovska-Coleska Z, McEachern D, Qiu S, Miller RS, Yi H, Shangary S, Sun Y, Meagher JL, Stuckey JA, Wang S (2008) SM-164: a novel, bivalent Smac mimetic that induces apoptosis and tumor regression by concurrent removal of the blockade of cIAP-1/2 and XIAP. Cancer Res 68: 9384

Mastrangelo E, Cossu F, Milani M, Sorrentino G, Lecis D, Delia D, Manzoni L, Drago C, Seneci P, Scolastico C, Rizzo V, Bolognesi M (2008) Targeting the $\mathrm{X}$-linked inhibitor of apoptosis protein through 4-substituted azabicyclo [5.3.0]alkane Smac mimetics. Structure, activity, and recognition principles. J Mol Biol 384: 673

Newsom-Davis T, Prieske S, Walczak H (2009) Is TRAIL the holy grail of cancer therapy? Apoptosis 14: $607-623$

Nikolovska-Coleska Z, Meagher JL, Jiang S, Kawamoto SA, Gao W, Yi H, Qin D, Roller PP, Stuckey JA, Wang S (2008) Design and characterization of bivalent Smac-based peptides as antagonists of XIAP and development and validation of a fluorescence polarization assay for XIAP containing both BIR2 and BIR3 domains. Anal Biochem 374: 87

Nikolovska-Coleska Z, Wang R, Fang X, Pan H, Tomita Y, Li P, Roller PP, Krajewski K, Saito NG, Stuckey JA, Wang S (2004) Development and optimization of a binding assay for the XIAP BIR3 domain using fluorescence polarization. Anal Biochem 332: 261

Oost TK, Sun C, Armstrong RC, Al-Assaad A, Betz SF, Deckwerth TL, Ding H, Elmore SW, Meadows RP, Olejniczak ET, Oleksijew A, Oltersdorf T, Rosenberg SH, Shoemaker AR, Tomaselli KJ, Zou H, Fesik SW (2004) Discovery of potent antagonists of the antiapoptotic protein XIAP for the treatment of cancer. J Med Chem 47: 4417-4426

Petersen SL, Wang L, Yalcin-Chin A, Li L, Peyton M, Minna J, Harran P, Wang X (2007) Cancer Cell 12: 445

Rozanov DV, Savinov AY, Golubkov VS, Rozanova OL, Postnova TI, Sergienko EA, Vasile S, Aleshin AE, Rega MF, Pellecchia M, Strongin AY (2009) Engineering a leucine zipper-TRAIL homotrimer with improved cytotoxicity in tumor cells. Mol Cancer Ther 8: 1515

Seneci P, Bianchi A, Battaglia C, Belvisi L, Bolognesi M, Caprini A, Cossu F, Franco ED, Matteo M de, Delia D, Drago C, Khaled A, Lecis D, Manzoni L, Marizzoni M, Mastrangelo E, Milani M, Motto I, Moroni E, Potenza D, Rizzo V, Servida F, Turlizzi E, Varrone M, Vasile F, Scolastico C (2009) Rational design, synthesis and characterization of potent, non-peptidic Smac mimics/XIAP inhibitors as proapoptotic agents for cancer therapy. Bioorg Med Chem 17: 5834

Sun H, Nikolovska-Coleska Z, Lu J, Qiu S, Yang C, Gao W, Meagher J, Stuckey J, Wang S (2006) Design, synthesis, and evaluation of a potent, cell-permeable, conformationally constrained second mitochondria derived activator of caspase (Smac) mimetic. J Med Chem 49: 7916-7920 
Takahashi R, Deveraux Q, Tamm I, Welsh K, Assa-Munt N, Salvesen GS, Reed JC (1998) A single BIR domain of XIAP sufficient for inhibiting caspases. J Biol Chem 273: 7787

Todaro M, Lombardo Y, Francipane MG, Alea MP, Cammareri P, Iovino F, Di Stefano, Di Bernardo C, Agrusa A, Condorelli G, Walczak H, Stassi G (2008) Apoptosis resistance in epithelial tumors is mediated by tumorcell-derived interleukin-4. Cell Death Differ 15: $762-772$

Varfolomeev E, Blankenship JW, Wayson SM, Fedorova AV, Kayagaki N, Garg P, Zobel K, Dynek JN, Elliott LO, Wallweber HJA, Flygare JA, Fairbrother WJ, Deshayes K, Dixit VM, Vucic D (2007) IAP antagonists induce autoubiquitination of c-IAPs, NF- $\mathrm{KB}$ activation, and $\mathrm{TNF} \alpha-$ dependent apoptosis. Cell 131: 669

Vince JE, Wong WW, Khan N, Feltham R, Chau D, Ahmed AU, Benetatos CA, Chunduru SK, Condon SM, McKinlay M, Brink R, Leverkus M, Tergaonkar V, Schneider P, Callus BA, Koentgen F, Vaux DL, Silke J (2007) Cell 131: 682

Vogler M, Walczak H, Stadel D, Haas TL, Genze F, Jovanovic M, Bhanot U, Hasel C, Moller P, Gschwend JE, Simmet T, Debatin K, Fulda S (2009) Small molecule XIAP inhibitors enhance TRAIL-induced apoptosis and antitumor activity in preclinical models of pancreatic carcinoma. Cancer Res 69: 2425-2434

Vogler M, Walczak H, Stadel D, Haas TL, Genze F, Jovanovic M, Gschwend JE, Simmet T, Debatin K, Fulda S (2008) Targeting XIAP bypasses Bcl-2-mediated resistance to TRAIL and cooperates with TRAIL to suppress pancreatic cancer growth in vitro and in vivo. Cancer Res 68: $7956-7965$

Walczak H, Degli-Esposti MA, Johnson RS, Smolak PJ, Waugh JY, Boiani N, Timour MS, Gerhart MJ, Schooley KA, Smith CA, Goodwin RG Rauch CT (1997) TRAIL-R2: a novel apoptosis-mediating receptor for TRAIL. EMBO J 16: $5386-5397$

Walczak H, Miller RE, Ariail K, Gliniak B, Griffith TS, Kubin M, Chin W, Jones J, Woodward A, Le T, Smith C, Smolak P, Goodwin RG, Rauch CT, Schuh JCL, Lynch DH (1999) Tumoricidal activity of tumor necrosis factor-related apoptosis-inducing ligand in vivo. Nat Med 5: 157-163

Wang L, Du F, Wang X (2008) Cell 133: 693

Wieder T, Essmann F, Prokop A, Schmelz K, Schulze-Osthoff K, Beyaert R, Dorken B, Daniel PT (2001) Activation of caspase- 8 in drug-induced apoptosis of B-lymphoid cells is independent of CD95/Fas receptorligand interaction and occurs downstream of caspase-3. Blood 97: $1378-1387$

Wu G, Chai J, Suber TL, Wu J, Du C, Wang X, Shi Y (2000) Structural basis of IAP recognition by Smac/DIABLO. Nature 408: 1008-1012

Zhang XD, Zhang XY, Gray CP, Nguyen T, Hersey P (2001) Tumor necrosis factor-related apoptosis-inducing ligand-induced apoptosis of human melanoma is regulated by Smac/DIABLO release from mitochondria. Cancer Res 61: 7339-7348 